\title{
SCRUTINIZATION OF JOULE HEATING AND VISCOUS DISSIPATION ON MHD FLOW AND MELTING HEAT TRANSFER OVER A STRETCHING SHEET
}

\author{
K.G. KUMAR and B.J. GIREESHA \\ Department of Studies and Research in Mathematics \\ Kuvempu University \\ Shankaraghatta-577 451, Shimoga, Karnataka, INDIA \\ E-mails: bjgireesu@gmail.com; ganikganesh@gmail.com \\ S. MANJUNATHA ${ }^{*}$ \\ Department of Engineering Mathematics \\ Faculty of Engineering, Christ University \\ Mysore Road, Bengaluru-560074 INDIA \\ E-mail: manjubhushana@gmail.com
}

\begin{abstract}
The present paper deals with an analysis of the combined effect of Joule heating and viscous dissipation on an MHD boundary layer flow and melting heat transfer of a micro polar fluid over a stretching surface. Governing equations of the problem are transformed into a set of coupled nonlinear ordinary differential equations by applying proper transformations and then they are solved numerically using the RKF-45 method. The method is verified by a comparison with the established results with limiting solution. The influence of the various interesting parameters on the flow and heat transfer is analyzed in detail through plotted graphs.
\end{abstract}

Key words: Joule heating, viscous dissipation, stretching sheet, micro polar dusty fluid, numerical method.

\section{Introduction}

Melting heat transfer effect has received much attention in recent years because of its important applications such as liquid polymer extrusion, frozen ground thawing, permafrost melting, casting and welding processes as well as phase change material, hot extrusion, polymers, ceramics and others is pushed or drawn through a die of the desired cross-section to produce different types of objects. Roberts [1] was the first to describe the steady melting of a body of ice which presents a plane surface transverse to a stream of hot air. Tien and Yen [2] studied the effect of melting on convective heat transfer between a melting body and surrounding fluid. Gorla et al. [3] studied the melting heat transfer in a mixed convection flow over a vertical plate. Meanwhile, the effect of melting heat transfer has been examined in several studies mentioned in [4]-[7] which involve flows of fluid over different geometry.

At present it is accepted that most of the fluids in industry and engineering are non-Newtonian in nature. The micropolar fluid model is a non-Newtonian fluid model which is adequate for exotic lubricants, animal blood, liquid crystals with rigid molecules, and certain biological fluids and colloidal or suspensions solutions. Eringen [8] was first who investigated micropolar fluids. This investigation shows that micro rotation effects as well as micro inertia have great potential for the discussion of flows of colloidal fluids, liquids crystal, polymeric suspension, and blood. Heruska et al. [9] studied the flow of an incompressible and constant density micropolar fluid past a porous stretching sheet and this study also extends the recent work of [10]-[17] to examine different non-Newtonian fluids.

\footnotetext{
${ }^{*}$ To whom correspondence should be addressed
} 
In recent years many researchers have examined a dusty fluid flow due to its wide range of applications such as fluidization, centrifugal separation of matter from fluid, purification of crude oil, dust collection, petroleum industry, powder technology, nuclear reactor cooling, performance of solid fuel rocket nozzles and paint spraying etc. Saffman [18] analyzed the flow of a dusty gas in which suspension particles are uniformly distributed. Further, Datta and Mishra [19] presented a boundary layer flow of a dusty fluid over a semi-infinite flat plate along with the drag force. Vajravelu and Nayfeh [20] analyzed a hydromagnetic flow of a dusty fluid over a stretching sheet with the effect of suction. Some more interrelated studies on nanofluids can be seen in [21-28].

The objective of this work is to analyze the effect of melting heat transfer of a micropolar dusty fluid over a stretching surface in the presence of Joule heating and viscous dissipation. Using suitable similarity transformations, the governing partial differential equations are reduced into a set of non-linear ordinary differential equations, and then they are solved numerically.

\section{Mathematical formulation}

Consider a steady boundary layer flow and heat transfer of a micropolar fluid towards a stretching sheet melting at a steady rate into a constant property warm liquid of the same material. The velocity of the stretching sheet is $u_{w}(x)=b x$, where $b$ is a constant and $x$ is the coordinate measured along the stretching sheet. It is also assumed that the temperature of the melting surface is $T_{m}$, while the temperature in the freestream condition is $T_{\infty}$, where $T_{\infty}>T_{m}$.

Governing equations after applying the boundary layer approximations are given by;

\section{Fluid phase}

$$
\begin{aligned}
& \frac{\partial u}{\partial x}+\frac{\partial v}{\partial y}=0 \\
& u \frac{\partial u}{\partial x}+v \frac{\partial u}{\partial y}=\left(v+\frac{k}{\rho}\right) \frac{\partial^{2} u}{\partial y^{2}}+\frac{K^{*} N^{*}}{\rho}\left(u_{p}-u\right)+\frac{k}{\rho} \frac{\partial N}{\partial y}-\frac{\sigma B^{2}}{\rho} u \\
& u \frac{\partial N}{\partial x}+v \frac{\partial N}{\partial y}=\frac{\gamma}{\rho j} \frac{\partial^{2} N}{\partial y^{2}}-\frac{k}{\rho j}\left(2 N+\frac{\partial u}{\partial y}\right) \\
& \left(u \frac{\partial T}{\partial x}+v \frac{\partial T}{\partial y}\right)=\frac{k^{*}}{c_{p} \rho} \frac{\partial^{2} T}{\partial y^{2}}+\frac{\rho_{p}}{\rho \tau_{T}}\left(T_{p}-T\right)+\frac{\rho_{p}}{\tau_{v}}\left(u_{p}-u\right)^{2}+\frac{\sigma B_{0}^{2}}{c_{p} \rho} u^{2}+\frac{v}{c_{p}}\left(\frac{\partial u}{\partial y}\right)^{2}
\end{aligned}
$$

\section{Dust phase}

$$
\begin{aligned}
& \frac{\partial u_{p}}{\partial x}+\frac{\partial v_{p}}{\partial y}=0 \\
& \rho_{p}\left(u_{p} \frac{\partial u_{p}}{\partial x}+v_{p} \frac{\partial u_{p}}{\partial y}\right)=K^{*} N^{*}\left(u-u_{p}\right), \\
& \rho_{p} c_{m}\left(u_{p} \frac{\partial T_{p}}{\partial x}+v_{p} \frac{\partial T_{p}}{\partial y}\right)=-\frac{\rho_{p C_{p}}}{\tau_{T}}\left(T_{p}-T\right),
\end{aligned}
$$


The boundary conditions are

$$
\begin{aligned}
& u=u_{w}(x), \quad N=-m \frac{\partial u}{\partial y}, \quad k\left(\frac{\partial T}{\partial y}\right)_{y \rightarrow 0}=\rho\left[E+C_{s}\left(T_{m}-T_{0}\right)\right] \mathrm{v}(x, 0) \text { at } \quad y=0, \\
& u=v=0, \quad u_{p} \rightarrow 0, \quad v_{p} \rightarrow v, \quad N \rightarrow 0, \quad T \rightarrow T_{m}, \quad T_{p} \rightarrow T_{m} \quad \text { as } \quad y \rightarrow \infty
\end{aligned}
$$

where $E$ is latent heat of the fluid and $C_{s}$ is heat capacity of the solid surface, heat conducted to melting surface is equal to heat of melting plus the sensible heat required to raise the solid temperature $T_{0}$ to its melting temperature $T_{m}$.

The following similarity transformations are introduced for the current problem

$$
\begin{aligned}
& u=b x f^{\prime}(\eta), \quad v=-\sqrt{v b} f(\eta), \quad N=u_{w}(x)\left(\frac{u_{w} x}{v x}\right)^{\frac{1}{2}} h(\eta), \quad \theta(\eta)=\frac{T-T_{\infty}}{T_{m}-T_{\infty}}, \\
& \eta=\sqrt{\frac{b}{v}} y, \quad u_{p}=b x F(\eta), \quad v_{p}=-\sqrt{v b} F(\eta), \quad \theta_{p}(\eta)=\frac{T_{p}-T_{m}}{T_{\infty}-T_{m}}
\end{aligned}
$$

where $T=T_{\infty}\left(1+\left(\theta_{w}-1\right) \theta\right)$, with $\theta_{w}=\frac{T_{m}}{T_{\infty}}, \theta_{w}>1$ being the temperature ratio parameter.

In view of (2.9), Eqs (2.1)-(2.7) are reduced as follows;

$$
\begin{aligned}
& (1+K) f^{\prime \prime \prime}+f f^{\prime \prime}-\left(f^{\prime}\right)^{2}+K h^{\prime}+l \beta_{v}\left[F^{\prime}-f^{\prime}\right]-Q f^{\prime}(\eta)=0, \\
& \left(1+\frac{K}{2}\right) h^{\prime \prime}+f h^{\prime}-f^{\prime} h-K\left(2 h+f^{\prime \prime}\right)=0, \\
& \theta^{\prime \prime}(\eta)+\operatorname{Pr} \theta^{\prime}(\eta) f(\eta)+l \operatorname{Pr} \beta_{T}\left(\theta_{p}(\eta)-\theta(\eta)\right)+ \\
& +\beta_{v} l \operatorname{Ec} \operatorname{Pr}\left[F^{\prime}(\eta)-f^{\prime}(\eta)\right]^{2}+\operatorname{Ec}\left[Q^{2} f^{\prime 2}+f^{\prime \prime 2}\right]=0, \\
& F F^{\prime \prime}-\left[F^{\prime}\right]^{2}+\beta_{v}\left[f^{\prime}-F^{\prime}\right]=0, \\
& \theta_{p}^{\prime}(\eta) F(\eta)-\gamma \beta_{T}\left[\theta_{p}(\eta)-\theta(\eta)\right]=0 .
\end{aligned}
$$

The corresponding boundary conditions are

$$
\begin{aligned}
& f(0)=0, \quad f^{\prime}(\eta)=1, \quad h(\eta)=-m f^{\prime \prime}(0), \operatorname{Pr} f(0)+M \theta^{\prime}(0)=0 \quad \text { at } \quad \eta=0, \\
& f^{\prime}(\eta)=0, F^{\prime}(\eta)=0, \quad F(\eta)=f(\eta), h(\eta)=0, \quad \theta(\eta) \rightarrow 1, \quad \theta_{p}(\eta) \rightarrow 1 \quad \text { as } \eta \rightarrow \infty .
\end{aligned}
$$


The physical quantities of interest are the skin friction coefficient $C_{f}$ and the local Nusselt number $\mathrm{Nu}_{x}$, which are defined as

$$
c_{f}=\frac{\tau_{w}}{\rho u_{w}^{2}}, \quad \text { and } \quad \mathrm{Nu}_{x}=\frac{u_{w} q_{w}}{b k\left(T_{\infty}-T_{w}\right)}
$$

where the shear stress $\left(\tau_{w}\right)$ and surface heat flux $\left(q_{w}\right)$ are given by,

$$
\tau_{w}=\left[(\mu+k)\left(\frac{\partial u}{\partial y}\right)\right]_{y \rightarrow 0}, \quad q_{w}=-k\left(\frac{\partial T}{\partial y}\right)_{y \rightarrow 0} .
$$

Using the non-dimensional variables, one can get

$$
\operatorname{Re}_{x}^{\frac{1}{2}} C_{f}=[1+(1-m) K] f^{\prime \prime}(0), \quad \frac{1}{\sqrt{\operatorname{Re}_{x}}} \mathrm{Nu}_{x}=-\theta^{\prime}(0)
$$

where $\operatorname{Re}_{x}=\frac{u_{w}^{2}}{a v}$ is the local Reynold's number.

\section{Result and discussion}

The set of similarity equalities (2.10) to (2.14) with boundary conditions (2.15) are highly coupled nonlinear differential equations and are difficult to solve analytically. So we seek for a numerical solution using the RKF-45 method. Table 1 shows the comparison of $f^{\prime \prime}(0)$ with the results reported by Akbar $e t$ al. [16] and Fathizadeh et al. [28], which show an excellent agreement. This confirms that the numerical results obtained are accurate. The numerical results for the local skin-friction coefficient and local Nusselt number are presented for different values of governing parameters in Tabs 2 and 3, respectively.

Table 1. Comparison of $f^{\prime \prime}(0)$ with the results by Akbar et al. [16] and Fathizadeh et al. [28], $(K=0)$ for different values of $M$.

\begin{tabular}{|cccc|}
\hline & Akbar et al. [16] & Fathizadeh et al. [28] & Present result \\
\hline 1 & -1.41421 & -1.41421 & -1.41421 \\
5 & -2.44948 & -2.44948 & -2.44949 \\
10 & -3.31662 & -3.31662 & -3.31662 \\
50 & -7.14142 & -7.14142 & -7.14143 \\
500 & -22.3830 & -22.3830 & -22.38302 \\
1000 & -31.6386 & -31.6386 & -31.63858 \\
\hline
\end{tabular}


Table 2. Numerical values of $[1+(1-m) K] f^{\prime \prime}(0),-\theta^{\prime}(0)$ and $-h^{\prime}(0)$ for different values of $\gamma, K, M, Q, m$ and $\beta_{v}$.

\begin{tabular}{|c|c|c|c|c|c|c|c|c|c|}
\hline$\gamma$ & $K$ & $M$ & $Q$ & $\beta_{v}$ & $l$ & $m$ & $-[1+(1-m) K] f^{\prime \prime}(0)$ & $-\theta^{\prime}(0)$ & $-h^{\prime}(0)$ \\
\hline 1 & & & & & & & -1.3826 & 2.0700 & 0.1718 \\
\hline 2 & & & & & & & -1.3803 & 2.1803 & 0.1709 \\
\hline \multirow{19}{*}{\multicolumn{2}{|c|}{0.5}} & & & & & & -1.3781 & 2.2863 & 0.1702 \\
\hline & & & & & & & -1.1963 & 1.9944 & 0.3061 \\
\hline & & & & & & & -1.3843 & 1.9901 & 0.1724 \\
\hline & & & & & & & -1.2284 & 1.9685 & 0.0945 \\
\hline & & 0 & & & & & -1.7963 & 2.3134 & 0.1876 \\
\hline & & 1 & & & & & -1.3528 & 1.7587 & 0.1614 \\
\hline & & 2 & & & & & -1.3075 & 1.4440 & 0.1464 \\
\hline & & & 1 & & & & -1.5955 & 2.0167 & 0.2260 \\
\hline & & & 2 & & & & -1.9503 & 2.0079 & 0.2908 \\
\hline & & & 3 & & & & -2.2495 & 1.9709 & 0.3468 \\
\hline & & & & 1 & & & -1.2979 & 1.9635 & 0.9614 \\
\hline & & & & 2 & & & -1.3054 & 1.9600 & 0.1750 \\
\hline & & & & 3 & & & -1.3090 & 1.9583 & 0.1756 \\
\hline & & & & & 0 & & -1.2750 & 1.9266 & 0.1699 \\
\hline & & & & & 0.2 & & -1.3052 & 2.0068 & 0.1748 \\
\hline & & & & & 0.4 & & -1.3346 & 2.0838 & 0.1796 \\
\hline & & & & & & 0.2 & -1.3122 & 1.9652 & 0.1493 \\
\hline & & & & & & 0.4 & -1.2674 & 1.9694 & 0.3003 \\
\hline & & & & & & 0.6 & -1.2188 & 1.9755 & 0.5696 \\
\hline
\end{tabular}


Table 3. Numerical values of $-\theta^{\prime}(\theta)$ for different values of $\operatorname{Ec}, \operatorname{Pr}, Q$ and $\beta_{t}$.

\begin{tabular}{|rrrr|}
\hline Ec & Pr & $\beta_{t}$ & $-\theta^{\prime}(0)$ \\
0 & & & 1.9897 \\
1 & & & 2.0331 \\
2 & & & 2.0764 \\
& 2 & & 1.6695 \\
& 3 & & 1.9901 \\
& 4 & & 3.7357 \\
& & 0 & 1.9319 \\
& & 0.5 & 1.9644 \\
& & 1 & 1.9740 \\
\hline
\end{tabular}

Figure 1 shows the behavior of $h(\eta)$ for higher values of the magnetic parameter $Q$. As expected, the angular velocity profile and the corresponding boundary layer thickness increase for increasing values of $Q$. Figure 2 depicts the effect of $Q$ on the dimensionless $f^{\prime}(\eta)$ and $F(\eta)$, respectively. It is explicit that $f^{\prime}(\eta)$ and $F(\eta)$ reduce with growing values of $Q$. It means that an application of a magnetic field normal to the flow of an electrically conducting fluid gives rise to a resistive force that acts in the direction opposite to that of the flow. This resistive force tends to slow down the motion of the fluid along the plate and causes a decrease in its velocity due to the buoyancy opposing flow.

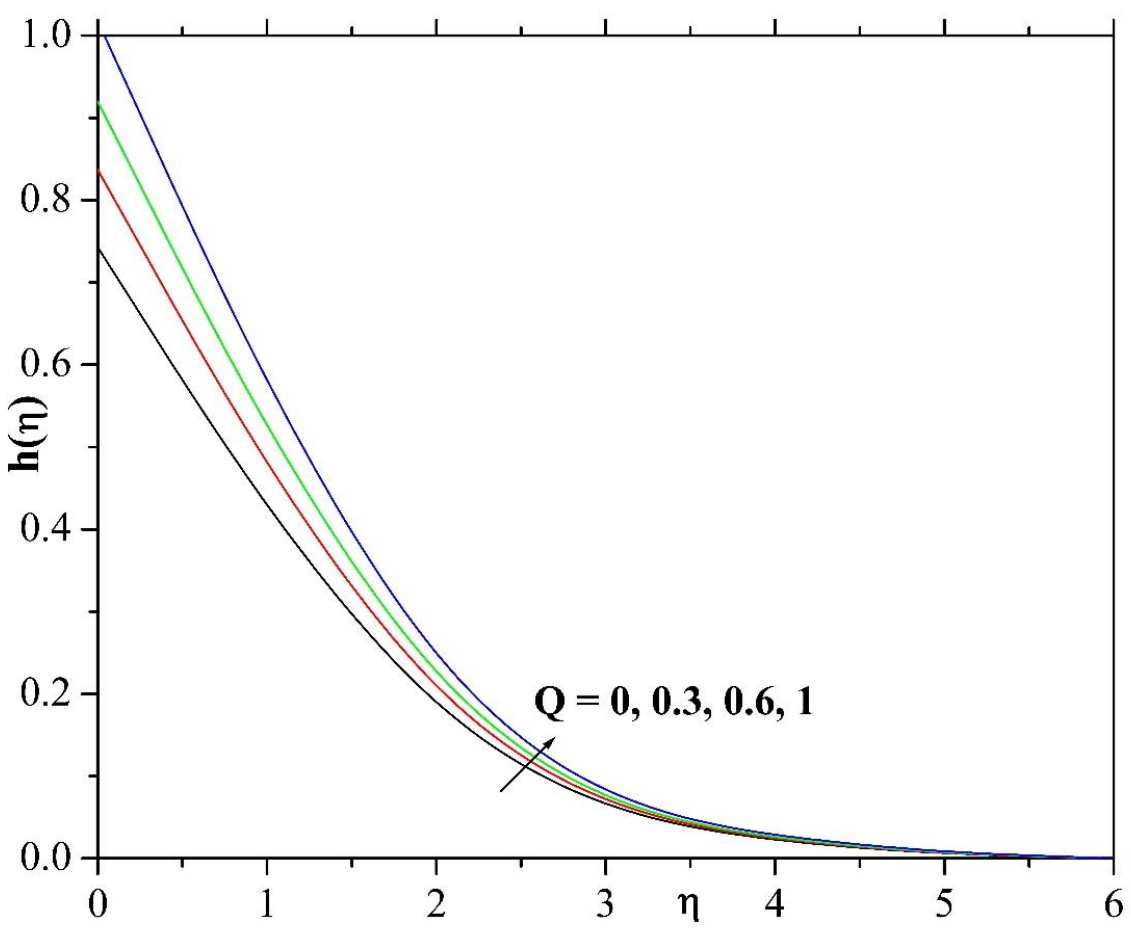

Fig.1. Angular velocity profile for different values of $Q$. 


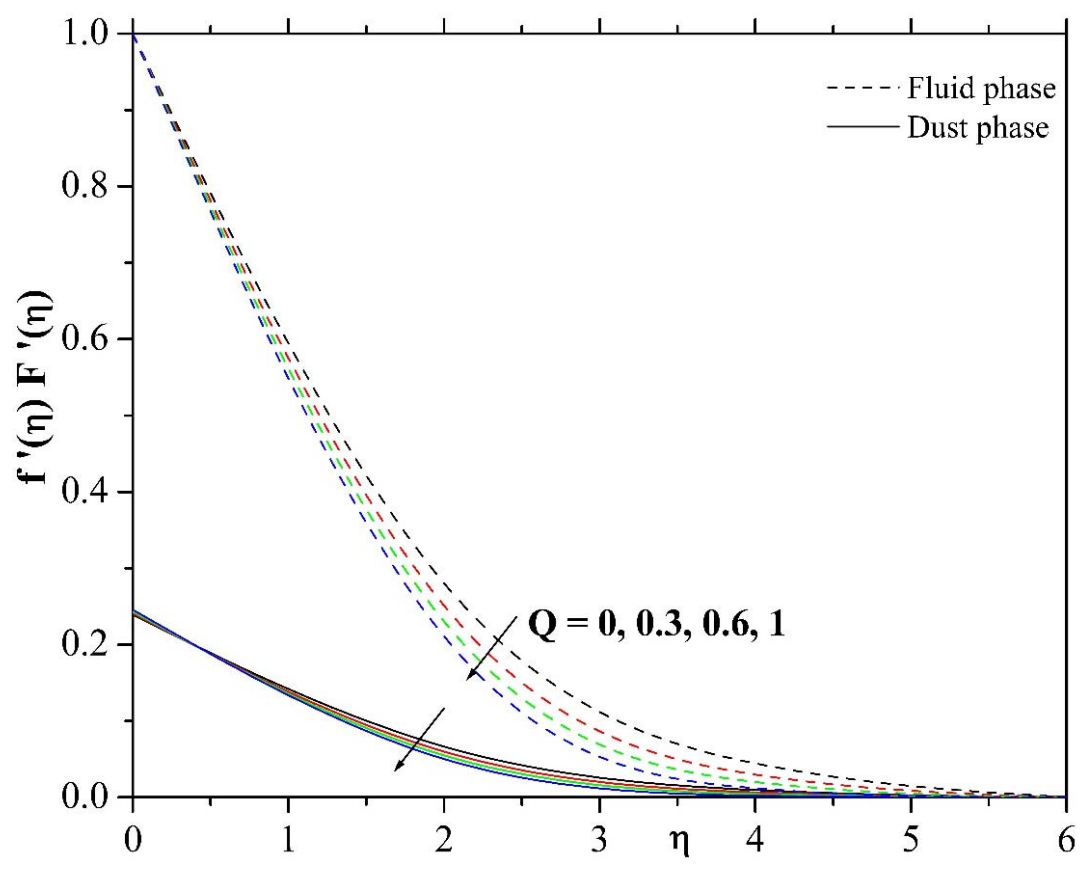

Fig.2. Velocity profile for different values of $Q$.

Figure 3 exemplifies the influence of the melting parameter $M$ on $f^{\prime}(\eta)$. An increase in $M$ enhances the velocity of both the fluid and dust phases and also the boundary layer thickness . Thus the sheet gradually transforms to a liquid causing the velocity profiles to grow rapidly. The effect of $M$ on the temperature profile is captured in Fig.4; one can observe from this figure that the temperature profile decreases for increasing values of $M$. Figure 5 represents the effect of $M$ on the angular velocity profile. It is observed that larger values of $M$ reduce $h(\eta)$.

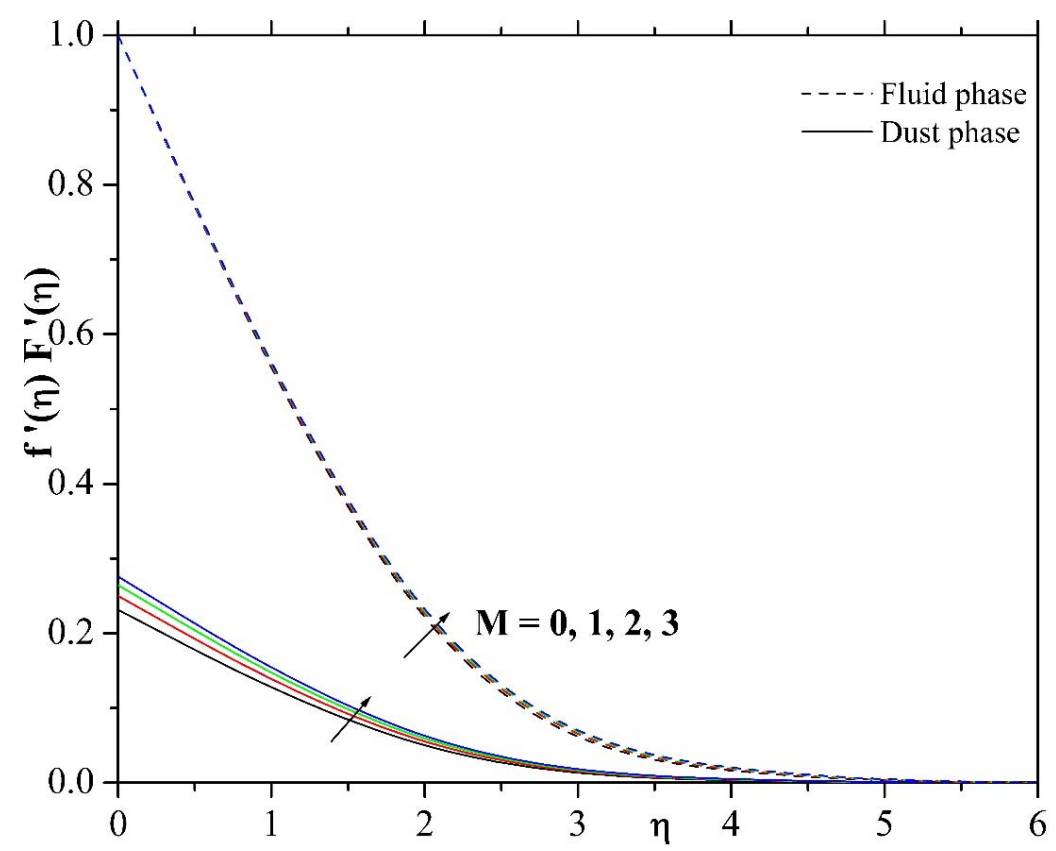

Fig.3. Angular velocity profile for different values of $M$. 


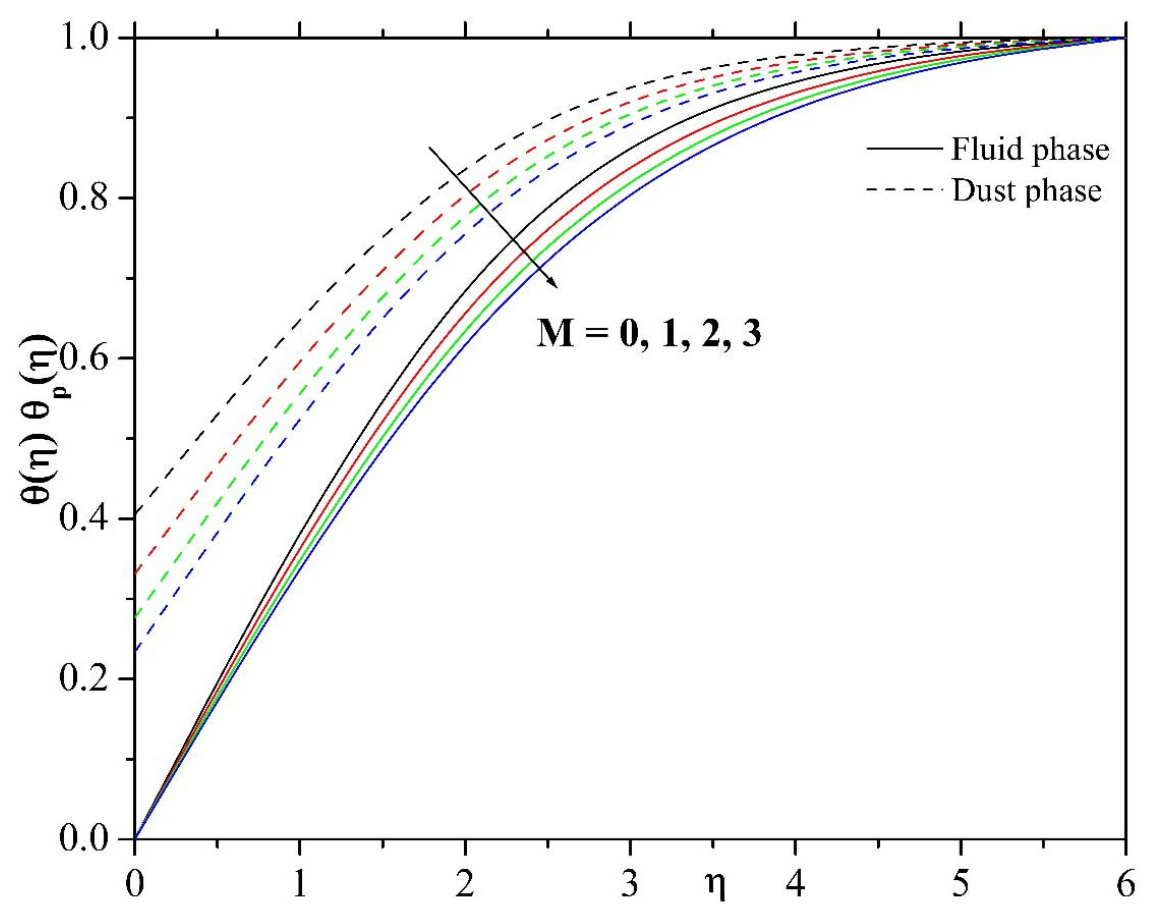

Fig.4. Temperature profile for different values of $M$.

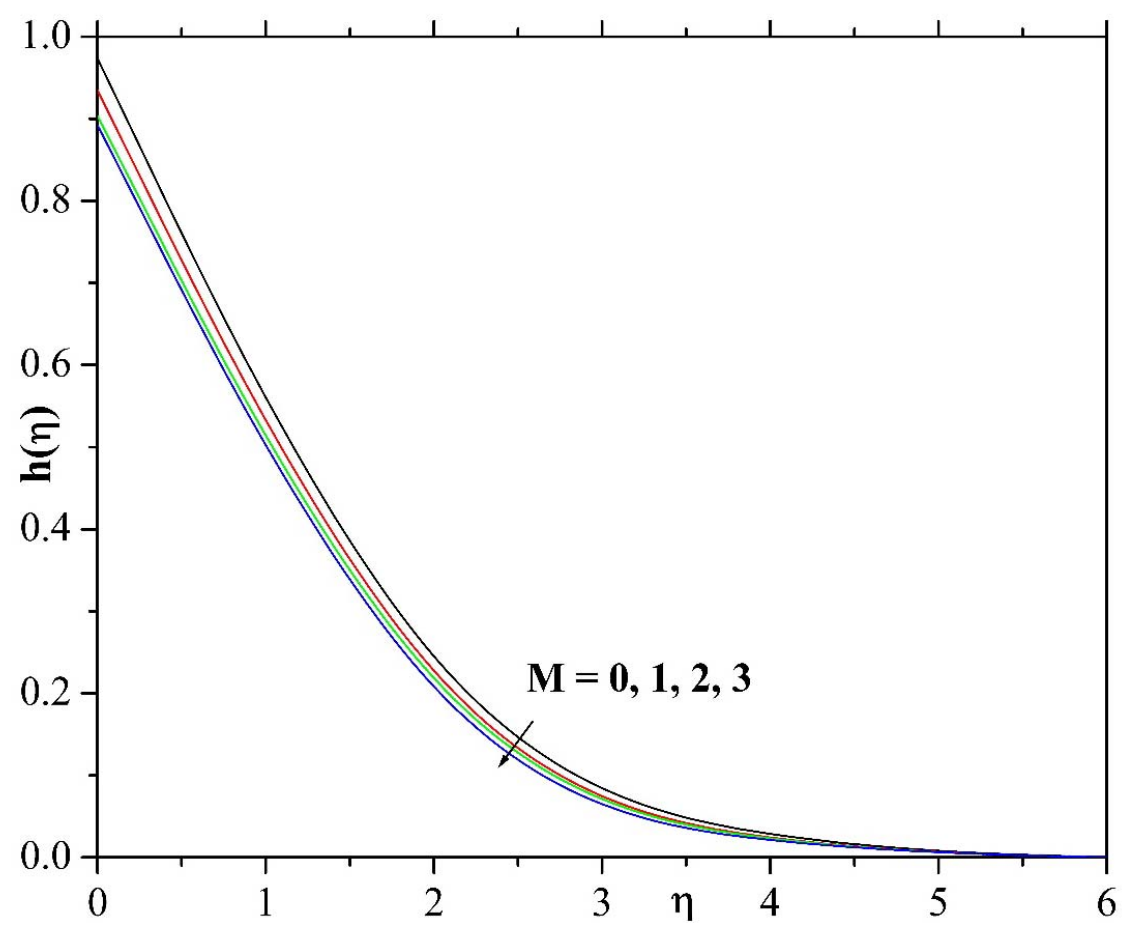

Fig.5. Angular velocity profile for different values of $M$.

Figure 6 depicts the effect of the material parameter $K$ on the velocity profile. The velocity profile of the both dust and fluid phase increases for growing values of $K$. Figure 7 shows the effect of $K$ on a $h(\eta)$. A growing values of $K$ increases the angular velocity profile. Figure 8 presents the effects of $m$ on 
the velocity profile. From this plot, it is observed that larger values of $m$ reduce the velocity profile as well as the momentum boundary layer thickness. Figure 9 shows the effect of $m$ on $h(\eta)$ and it reveals that $h(\eta)$ increases as $m$ increases.

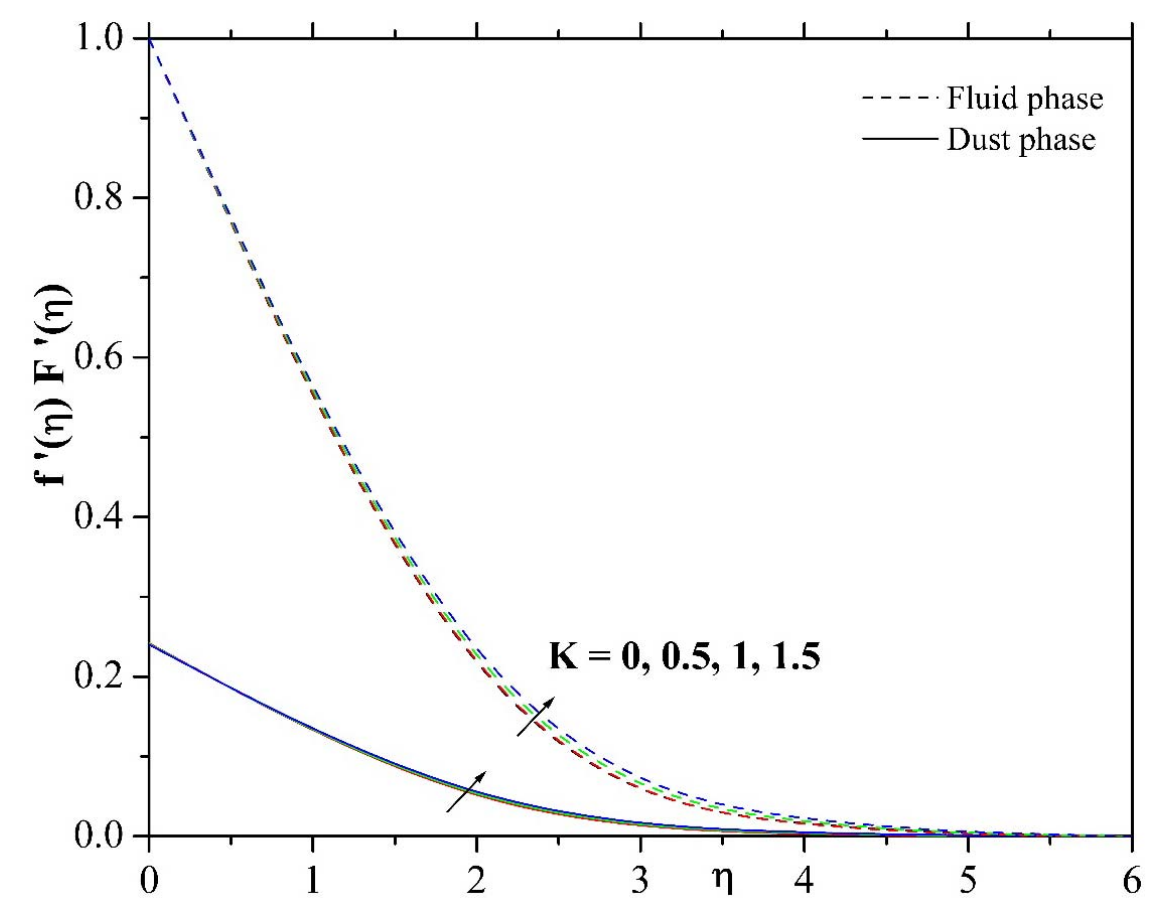

Fig.6. Velocity profile for different values of $K$.

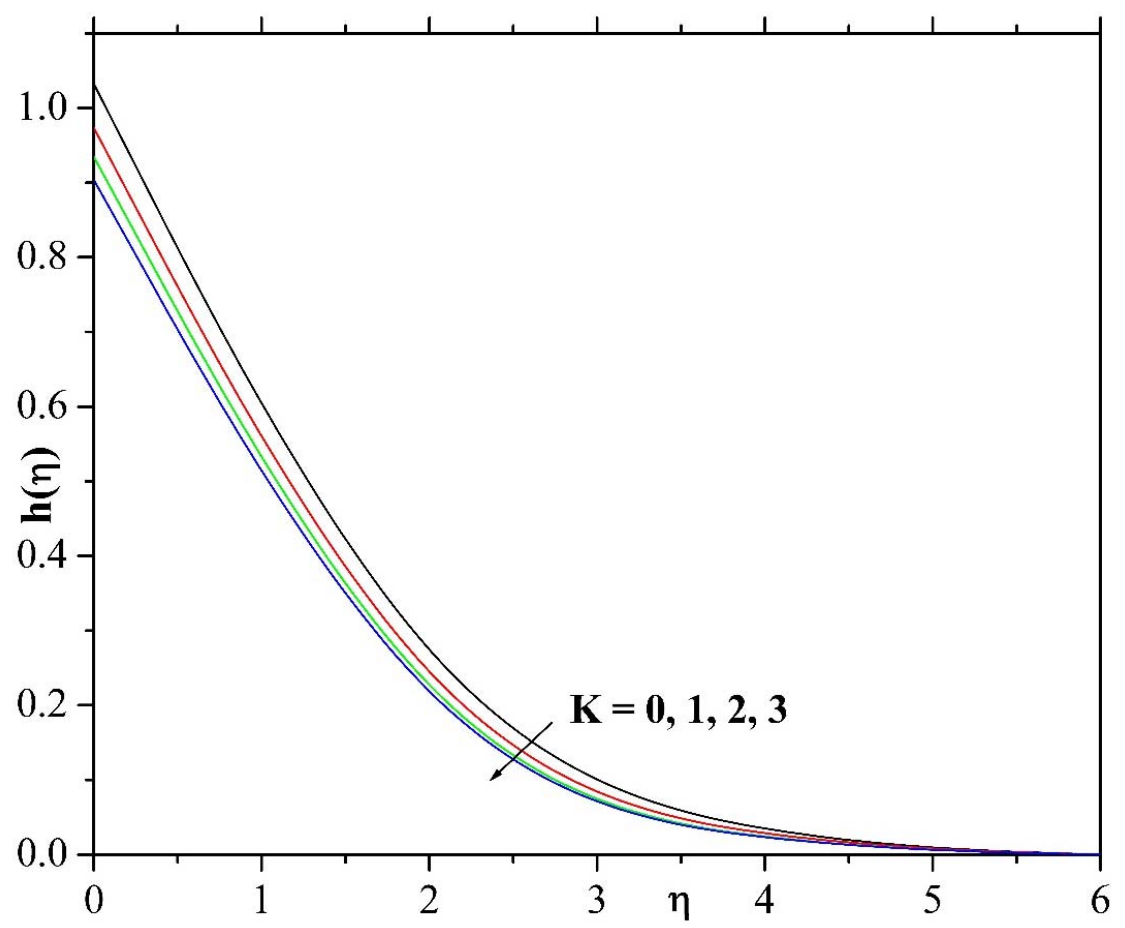

Fig.7. Angular velocity profile for different values of $K$. 


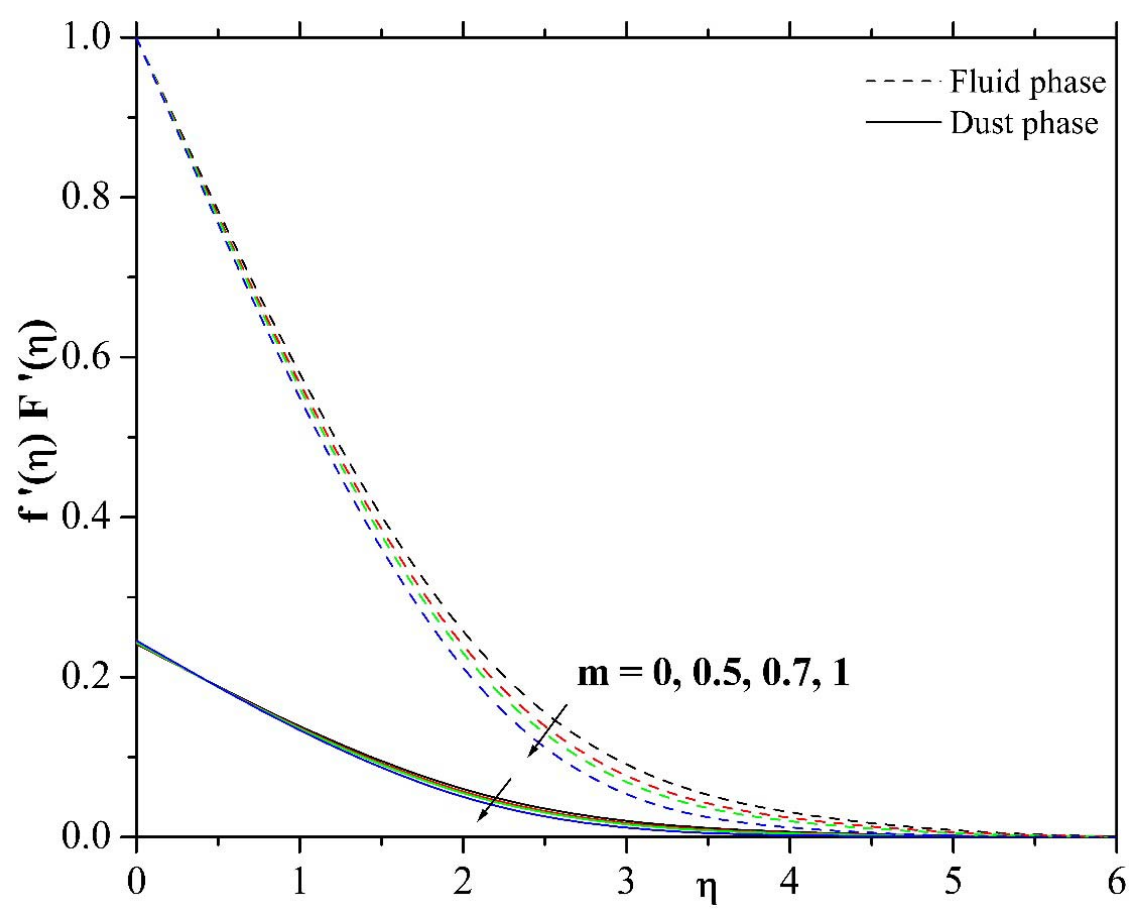

Fig.8. Velocity profile for different values of $m$.

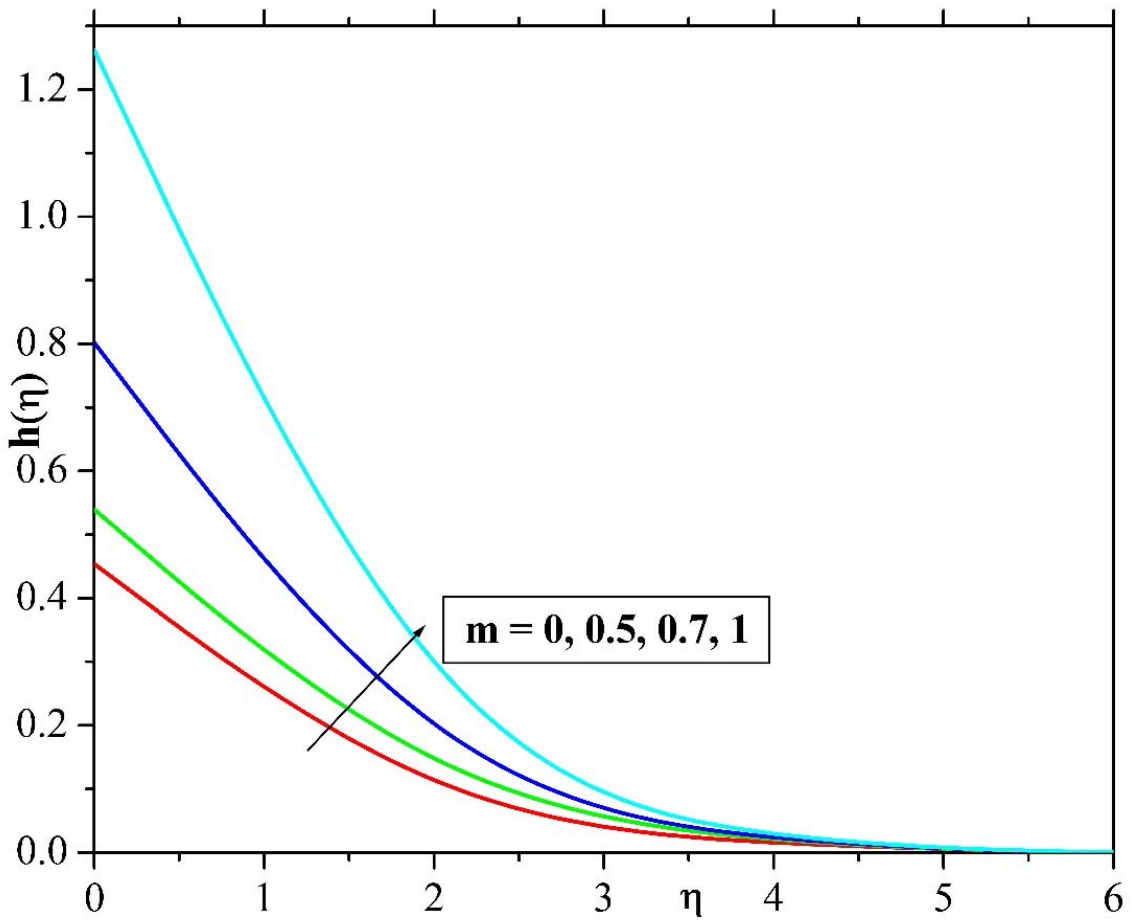

Fig.9. Angular velocity profile for different values of $m$.

Figure 10 illustrates the effect of the Prandtl number $(\operatorname{Pr})$ on the temperature profile. In the presence of the melting parameter, the temperature profile for the both fluid and dust phase increases for increasing values of Pr. On the other hand, an expected result was obtained for the influence of the specific heat ratio 
$(\gamma)$ for both the fluid and dust phase of the temperature profile as shown in Fig.11. From this figure, it follows that an increase in the specific heat ratio parameter increases the temperature profile and thermal boundary layer thickness rapidly. Figure 12 depicts the effect of the Eckert number Ec on the dimensionless $\theta(\eta)$ and $\theta_{p}(\eta)$. This figure reveals that the effect of increasing values of $E c$ is to increase temperature distribution of both the fluid and dust phase in the flow region.

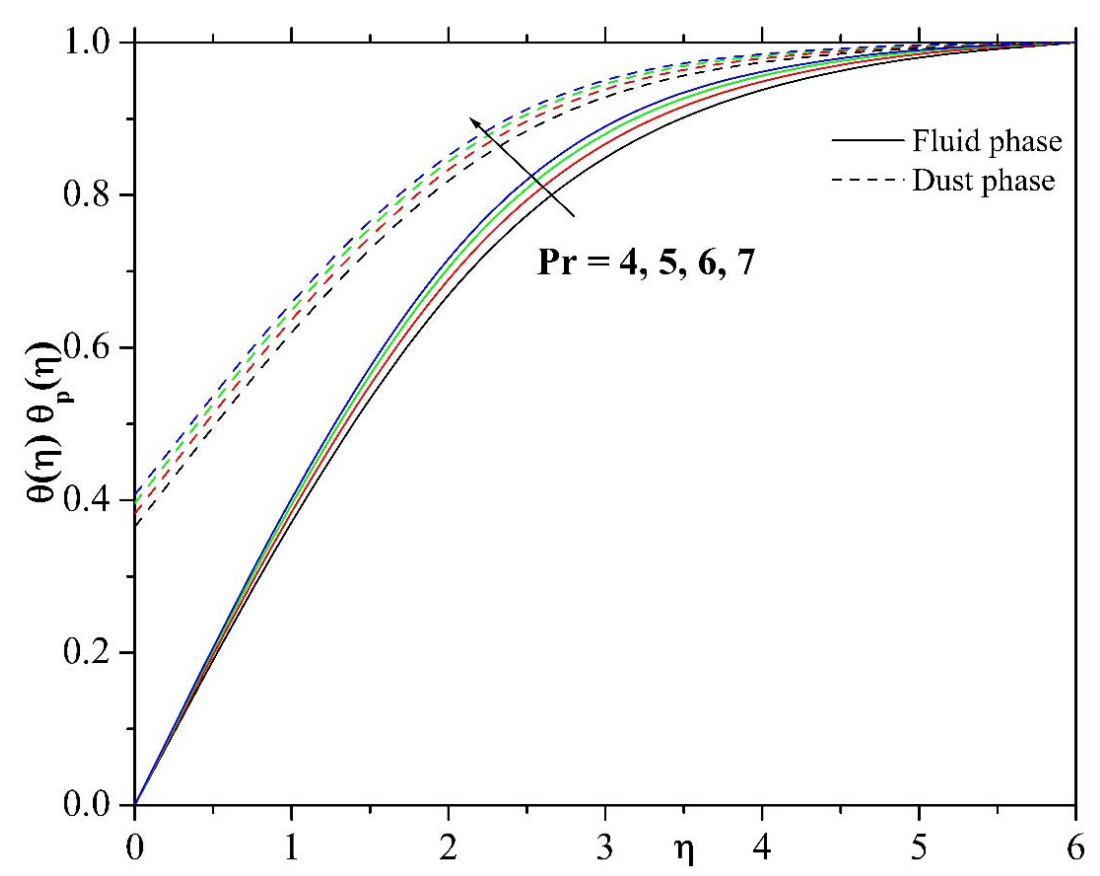

Fig.10. Temperature profile for different values of Pr.

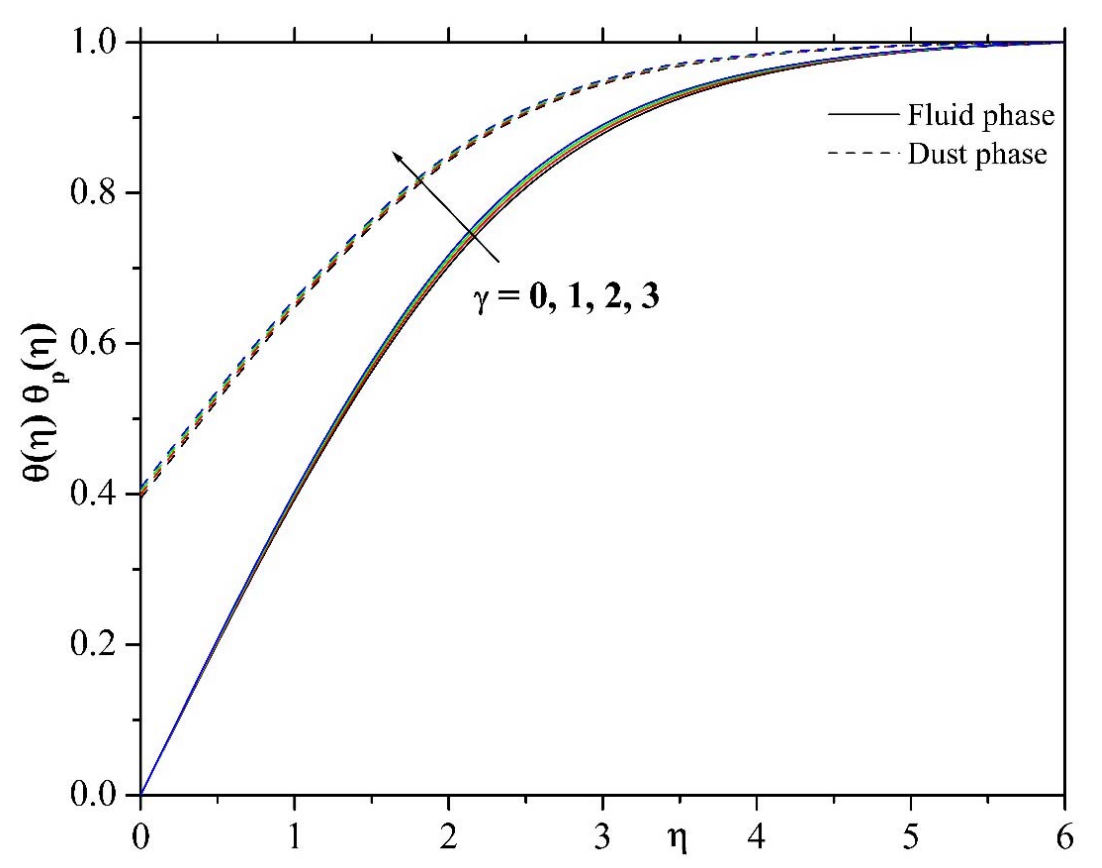

Fig.11. Temperature profile for different values of $\gamma$. 


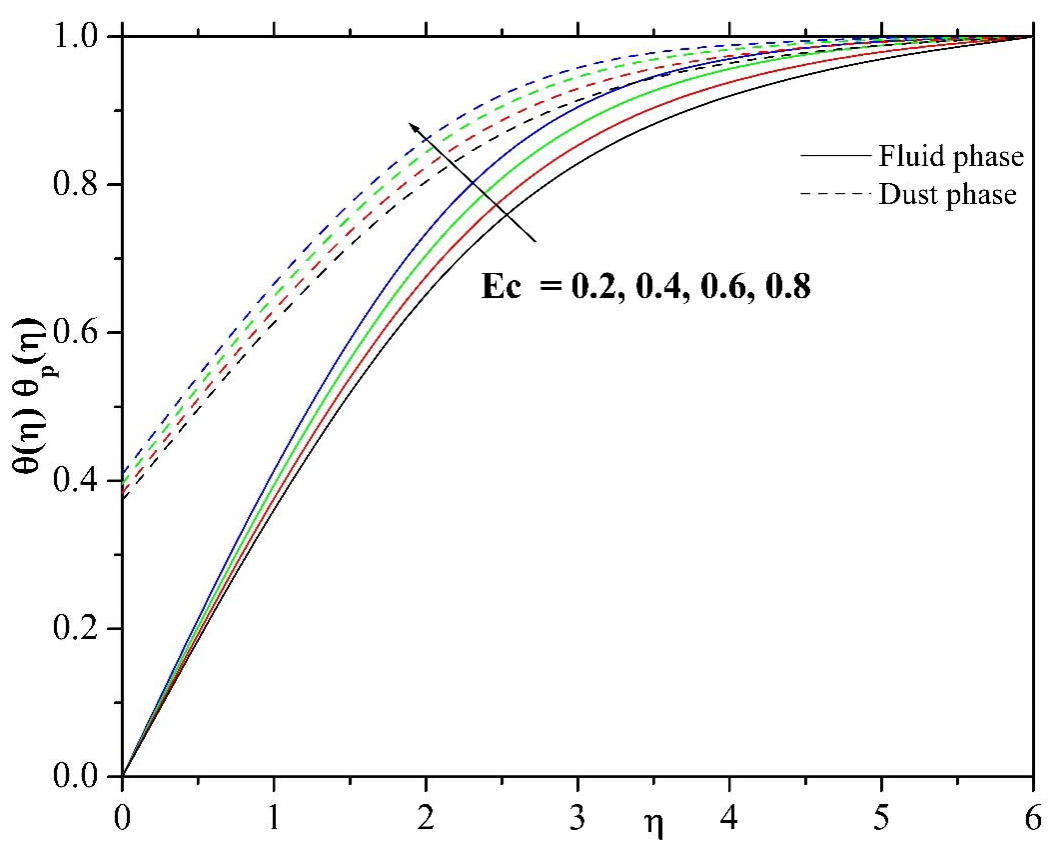

Fig.12. Temperature profile for different values of Ec.

\section{Conclusion}

This study shows the effect of Joule heating and viscous dissipation on an MHD boundary layer flow and melting heat transfer of a micropolar fluid over a stretching surface with fluid particles suspension. Some important features regarding the effect of different physical parameters on flow fields are reported. The main results of the problem are summarized as follows:

- The momentum boundary layer thickness reduces due to the influence of the Lorentz force.

- A larger value of $Q$ and $K$ leads to an increase in the momentum boundary layer thickness which reduces the velocity and temperature of the fluid.

- Increasing values of the melting parameter increase the momentum boundary layer thickness and reduce the thermal boundary layer thickness.

- Temperature profile enhances for increasing values of Pr.

$\circ$ The rate of hear transfer increases for increasing values of $\gamma$.

$\circ$ Both the fluid and dusty phase temperature increases for increasing values of Ec.

\section{Nomenclature}

$B_{0}^{2} \quad$ - magnetic field

$b$ - stretching rate

$C_{f}-$ skin friction coefficient

$c_{m}$ - dust phase specific heat coefficient $(J / \mathrm{kgK})$

$c_{p} \quad$ - fluid phase specific heat coefficient $(J / \mathrm{kgK})$

$\frac{c_{f}\left(T_{\infty}-T_{m}\right)}{\lambda}-$ Stefan number for the liquid phase

$\frac{c_{s}\left(T_{m}-T_{0}\right)}{\lambda}-$ Stefan number for the solid phases

Ec - Eckert number 


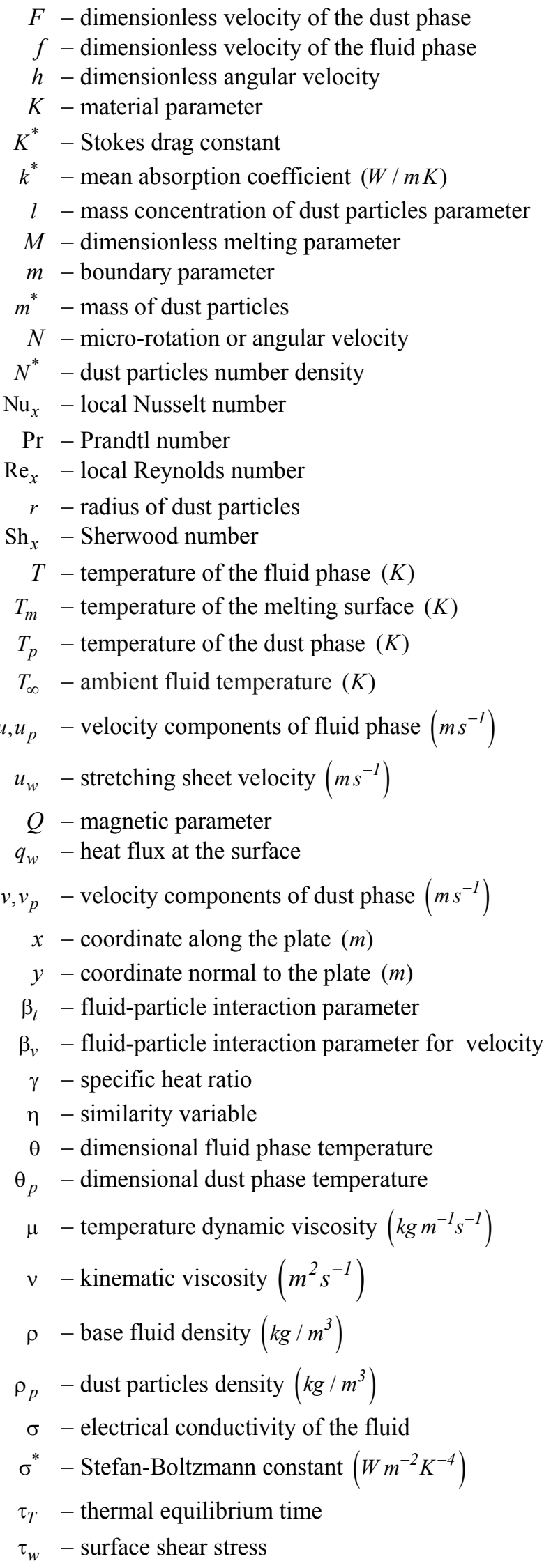


$\tau_{v} \quad$ - dust particles relaxation time

\section{Superscript}

' - derivative with respect to $\eta$

\section{Subscript}

$$
\begin{array}{ll}
p & - \text { particle phase } \\
\infty & - \text { fluid properties at ambient condition }
\end{array}
$$

\section{Reference}

[1] Roberts L. (1958): On the melting of a semi-infinite body of ice placed in a hot stream of air. - J. of Fluid Mechanics, vol.4, pp.505-528.

[2] Tien C. and Yen Y.C. (1965): The effect of melting on forced convection heat transfer. - J. Appl. Meteorol, vol.4, pp.523-527.

[3] Gorla R.S.R., Mansour M.A., Hussanien I.A. and Bakier A.Y. (1999): Mixed convection effect on melting from a vertical plate. - Transport Porous Med., vol.36, pp.245-254.

[4] Ganesh Kumar K., Gireesha B.J., Rudraswamy N.G. and Gorla R.S.R. (2017): Melting heat transfer of hyperbolic tangent fluid over a stretching sheet with fluid particle suspension and thermal radiation. Communications in Numerical Analysis, vol.2, pp.125-140.

[5] Hayat T., Anum Shafiq and Alsaedi A. (2016): Characteristics of magnetic field and melting heat transfer in stagnation point flow of Tangent-hyperbolic liquid. - Journal of Magnetism and Magnetic Materials, vol.405, pp.97-106.

[6] Ganesh Kumar K., Gireesha B.J., Prasannakumara B.C. and Ramesh G.K. (2017): Phenomenon of radiation and viscous dissipation on Casson nanoliquid flow past a moving melting surface. - Diffusion Foundations, vol.11, pp.33-42.

[7] Makinde O.D., Kumar K.G., Manjunatha S. and Gireesha B.J. (2017): Effect of nonlinear thermal radiation on MHD boundary layer flow and melting heat transfer of micro-polar fluid over a stretching surface. - Defect and Diffusion Forum, vol.378, pp.125-136.

[8] Eringen A.C. (1966): Theory of micropolar fluids. - J. Math. Mech., vol.16, pp.150-178.

[9] Heruska M.W., Watson L.T. and Sankara K.K. (1986): Micropolar flow past a porous stretching sheet. Comput. Fluids, vol.14, pp.117-29.

[10] Hassanien I.A. and Gorla R.S.R. (1990): Heat transfer to a micropolar fluid from a non-isothermal stretching sheet with suction and blowing. - Acta Mechanica, vol.84, pp.191-199.

[11] Nazar R., Amin N., Filip D. and Pop I. (2004): Stagnation point flow of a micropolar fluid towards a stretching sheet. - Int. J. of Non-Linear Mechanics, vol.39, No.7, pp.1227-1235.

[12] Khalid A., Ilyas Khan and Sharidan Shafie (2017): Free convection flow of micropolar fluids over an oscillating vertical plate. - Malaysian Journal of Fundamental and Applied Sciences, vol.13, No.4, pp.654-658.

[13] Kumar K.G., Rudraswamy N.G., Gireesha B.J. and Manjunatha S. (2017): Nonlinear thermal radiation effect on Williamson fluid with particle-liquid suspension past a stretching surface. - Results in Physics, vol.7, pp.3196-3202.

[14] Govardhan K., Nagaraj G., Kaladhar K. and Balasiddulu M. (2015): MHD and radiation effects on mixed convection unsteady flow of micropolar fluid over a stretching sheet. - Procedia Computer Science, vol.57, pp.65-76. 
[15] Kumar K.G., Gireesha B.J., Manjunatha S. and Rudraswamy N.G. (2017): Effect of nonlinear thermal radiation on double-diffusive mixed convection boundary layer flow of viscoelastic nanofluid over a stretching sheet. International Journal of Mechanical and Materials Engineering, vol.12, No.1, pp.18.

[16] Akbar N.S., Nadeem S., Haq R. and Khan Z.H. (2013): Numerical solutions of magneto hydrodynamic boundary layer flow of tangent hyperbolic fluid flow towards a stretching sheet with magnetic field. - Indian J. Phys., vol.87, No.11, pp.1121-1124.

[17] Kumar K.G., Gireesha B.J., Ramesh G.K. and Rudraswamy N.G. (2018): Double-diffusive free convective flow of Maxwell nanofluid past a stretching sheet with nonlinear thermal radiation. - Journal of Nanofluids, vol.7, No.3, pp.499-508.

[18] Sa man P.G. (1962): On the stability of laminar flow of a dusty gas. - J. of Fluid Mechanics, vol.13, pp.120128.

[19] Datta N. and Mishra S.K. (1982): Boundary layer flow of a dusty fluid over a semi-infinite flat plate. - Acta Mech., vol.42, pp.71-83.

[20] Vajravelu K. and Nayfeh J. (1992): Hydromagnetic flow of a dusty fluid over a stretching sheet. - Int. J. of Nonlinear Mechanics, vol.27, pp.937-945.

[21] Gireesha B.J., Manjunatha S. and Bagewadi C.S. (2012): Unsteady hydromagnetics boundary layer flow and heat transfer of dusty fluid over a stretching sheet. - Afrika Matematika, vol.23, No.2, pp.229-241.

[22] Gireesha B.J., Chamkha A.J. and Manjunatha S. (2013): Boundary-layer flow and heat transfer of a dusty fluid flow over a stretching sheet with non-uniform heat source/sink and radiation. - Int. J. Numer. Methods Heat Fluid Flow, vol.23, No.4, pp.598-612.

[23] Manjunatha S. and Gireesha B.J. (2016): Effects of variable viscosity and thermal conductivity on MHD flow and heat transfer of a dusty fluid. - Ain Shams Engineering Journal, vol.7, No.1, pp.505-515.

[24] Kumar K.G., Gireesha B.J. and Gorla R.S.R. (2018): Flow and heat transfer of dusty hyperbolic tangent fluid over a stretching sheet in the presence of thermal radiation and magnetic field. - International Journal of Mechanical and Materials Engineering, vol.13, No.1, 2.

[25] Ramesh G.K., Kumar K.G., Shehzad S.A. and Gireesha B.J. (2018): Enhancement of radiation on hydromagnetic Casson fluid flow towards a stretched cylinder with suspension of liquid-particles. - Canadian Journal of Physics, vol.999, pp.1-7.

[26] Kumar K.G., Gireesha B.J., Rudraswamy N.G. and Manjunatha S. (2017): Radiative heat transfers of Carreau fluid flow over a stretching sheet with fluid particle suspension and temperature jump. - Results in Physics, vol.7, pp.3976-3983.

[27] Reddy M.G., Rani M.S., Kumar K.G. and Prasannakumara B.C. (2018): Cattaneo-Christov heat flux and nonuniform heat-source/sink impacts on radiative Oldroyd-B two-phase flow across a cone/wedge. - Journal of the Brazilian Society of Mechanical Sciences and Engineering, vol.40, No.20, 95.

[28] Fathizadeh M., Madani M., Khan Y., Faraz N., Yildirim A. and Tutkun S. (2013): An effective modification of the homotopy perturbation method for MHD viscous flow over a stretching sheet. - J. King Saud University, vol.25, No.2, pp.107-113.

Received: March 28, 2017

Revised: March 21, 2018 